\title{
Analysis of the Interaction between Globular Head Modules of Human C1q and Its Candidate Receptor gC1qR
}

\begin{abstract}
Lina Pednekar', Ansar A. Pathan', Basudev Paudyal', Anthony G. Tsolaki', Anuvinder Kaur', Suhair M. Abozaid', Lubna Kouser', Haseeb A. Khan'2, Ellinor I. Peerschke', Mohamed H. Shamjit, Gudrun Stenbeck ${ }^{1}$, Berhane Ghebrehiwet ${ }^{5 *}$ and Uday Kishore ${ }^{1 *}$

'Biosciences, College of Health and Life Sciences, Brunel University London, London, UK, ${ }^{2}$ Department of Biochemistry, College of Science, King Saud University, Riyadh, Saudi Arabia, ${ }^{3}$ Department of Laboratory Medicine, Memorial Sloan-Kettering, Cancer Center, New York, NY, USA, ${ }^{4}$ Allergy and Clinical Immunology, National Heart and Lung Institute, Imperial College London, London, UK, ${ }^{5}$ Department of Medicine, State University of New York, Stony Brook, NY, USA
\end{abstract}

\section{OPEN ACCESS}

Edited by:

Cordula M. Stover

University of Leicester, UK

Reviewed by:

Robert Braidwood Sim,

University of Leicester, UK

Goran Bajic,

Harvard Medical School, USA

${ }^{*}$ Correspondence:

Berhane Ghebrehiwet berhane.ghebrehiwet@ stonybrookmedicine.edu;

Uday Kishore

uday.kishore@brunel.ac.uk,

ukishore@hotmail.com

Specialty section:

This article was submitted to Molecular Innate Immunity, a section of the journal

Frontiers in Immunology

Received: 04 July 2016 Accepted: 22 November 2016 Published: 13 December 2016

Citation:

Pednekar L, Pathan AA, Paudyal B, Tsolaki AG, Kaur A, Abozaid SM, Kouser L, Khan HA, Peerschke El, Shamii MH, Stenbeck G,

Ghebrehiwet $B$ and Kishore $U$ (2016) Analysis of the Interaction between Globular Head

Modules of Human C1q and lts Candidate Receptor gC1qR. Front. Immunol. 7:567. doi: 10.3389/fimmu.2016.00567
The heterotrimeric globular head $(\mathrm{gC} 1 \mathrm{q})$ domain of human $\mathrm{C} 1 \mathrm{q}$ is made up of the C-terminal ends of the three individual chains, ghA, ghB, and ghC. A candidate receptor for the $\mathrm{gC} 1 \mathrm{q}$ domain is a multi-functional pattern recognition protein, $\mathrm{gC} 1 \mathrm{qR}$. Since understanding of $\mathrm{gC} 1 \mathrm{qR}$ and $\mathrm{gC} 1 \mathrm{q}$ interaction could provide an insight into the pleiotropic functions of $\mathrm{gC} 1 \mathrm{qR}$, this study was undertaken to identify the $\mathrm{gC} 1 \mathrm{qR}$-binding site on the gC1q domain, using the recombinant ghA, ghB, and ghC modules and their substitution mutants. Our results show that ghA, ghB, and ghC modules can interact with $\mathrm{gC} 1 \mathrm{qR}$ independently, thus reinforcing the notion of modularity within the $\mathrm{gC} 1 \mathrm{q}$ domain of human C1q. Mutational analysis revealed that while Arg162 in the ghA module is central to interaction between $\mathrm{gC} 1 \mathrm{qR}$ and $\mathrm{C} 1 \mathrm{q}$, a single amino acid substitution (arginine to glutamate) in residue 114 of the ghB module resulted in enhanced binding. Expression of $\mathrm{gC} 1 \mathrm{qR}$ and $\mathrm{C} 1 \mathrm{q}$ in adherent monocytes with or without pro-inflammatory stimuli was also analyzed by qPCR; it showed an autocrine/paracrine basis of C1q and $\mathrm{gC1} \mathrm{qR}$ interaction. Microscopic studies revealed that $\mathrm{C} 1 \mathrm{q}$ and $\mathrm{gC} 1 \mathrm{qR}$ are colocalized on PBMCs. Cell proliferation assays indicated that ghA, ghB, and ghC modules were able to attenuate phytohemagglutinin-stimulated proliferation of PBMCs. Addition of gC1qR had an additive effect on the anti-proliferative effect of globular head modules. In summary, our results identify residues involved in C1q-gC1qR interaction and explain, to a certain level, their involvement on the immune cell surface, which is relevant for C1q-induced functions including inflammation, infection, and immunity.

Keywords: C1q, globular head, gC1qR, protein-protein interaction, cell proliferation

\section{INTRODUCTION}

$\mathrm{C} 1 \mathrm{q}$ is the first subcomponent of the classical pathway of the complement system that links innate and adaptive immunity by virtue of recognizing IgG and IgM in the immune complexes (1). Structurally, human $\mathrm{Clq}(460 \mathrm{kDa})$ is made up of 18 polypeptides, i.e., $6 \mathrm{~A}, 6 \mathrm{~B}$, and $6 \mathrm{C}$ chains. Each chain has a short $\mathrm{N}$-terminal region, a collagen-like region (CLR), and a C-terminal globular head (gClq) domain (2). A combination of interchain disulfide bond formation and triple-helical CLR gives rise to an ABC-CBA structural subunit. Three of these subunits associate to yield the hexameric 
C1q molecule. The gC1q domain is a hetrotrimeric structure composed of C-terminal halves of A, B, and C chains. C1q is able to bind to an array of self, non-self, and altered-self ligands (3-7) via its gC1q domain (8). This ligand-binding versatility of $\mathrm{Clq}$ is offered by the modular organization of the individual globular head (gh) modules, ghA, ghB, and ghC, which are considered structurally and functionally independent (9-12).

A candidate receptor that binds to the $\mathrm{gClq}$ domain of human $\mathrm{C1q}$, called gC1qR (33 kDa), is a highly acidic, multi-ligand binding, and multi-functional protein. In addition to its role in the complement system, $\mathrm{gClqR}$ is also involved in blood clotting via interaction with thrombin and vitronectin (13). Furthermore, as a high affinity receptor for high molecular weight kininogen and FXII, gC1qR present on the endothelial cells is able to serve as a major platform for the activation of the kinin/kallikrein, leading to the generation of the vasoactive peptide, bradykinin $(14,15)$.

Although the $\mathrm{gClq}-\mathrm{gClqR}$ interaction has been described previously (16), the complementary binding sites and the precise nature of interaction remain to be fully established. The major gC1q-binding site on $\mathrm{gClqR}$ has been shown to be located on residues 76-93 based on peptides studies (17). The availability of the recombinant individual gh modules, ghA, ghB, and ghC, which represent globular region of $A, B$, and $C$ chains, respectively, without collagen region of $\mathrm{C1q}$ (18) has given us the opportunity to examine the $\mathrm{gClq}-\mathrm{gClqR}$ interaction more closely. With respect to the structure/function relationship within the $\mathrm{gClq}$ domain $(19,20)$, it is now known that ghA, ghB, and ghC are functionally independent modules. The modular organization of the $\mathrm{gClq}$ domain offers $\mathrm{Clq}$, the versatility required for binding to a range of self and non-self ligands. This is evident in the case of the HIV-1 gp41 peptide 601-613, which preferentially binds to ghA (20), and the $\beta$-amyloid peptide specifically interacting with ghB (20).

The crystal structure of $\mathrm{gC} 1 \mathrm{qR}$ has revealed three monomers held together to form a trimer (21). Each monomer consists of seven anti-parallel $\beta$ strands filled by an $\mathrm{N}$-terminal and two C-terminal $\alpha$ helices. gC1qR has a distinct charge distribution, with the "solution face" of its "donut" shaped structure that is highly negatively charged and exposed to the plasma, while the reverse side or "membrane face" is neutral or basic (17). The C1q binding site, residues 76-93, is exposed only on the highly charged solution face (17). Since the C1q binding site on $\mathrm{gC1}$ qR has been identified, we sought to identify the complementary residues on the $\mathrm{gClq}$ domain that are involved in the $\mathrm{gClq}-\mathrm{gC} 1 \mathrm{qR}$ interaction. Previous studies have highlighted $\mathrm{Arg}^{\mathrm{B} 114}$ and $\mathrm{Arg}^{\mathrm{B} 129}$ of the $\mathrm{B}$ chain to be central in the C1q-IgG interaction (22). It has also been shown that $\mathrm{Clq}$ binding to $\mathrm{gClqR}$ on platelets (23) and endothelial cells (24) induces complement activation independent of IgG. Furthermore, although gC1qR has been shown to bind to the $\mathrm{gClq}$ domain of $\mathrm{Clq}$, its physiological relevance still remains to be established.

Here, we have examined the interaction of recombinant forms of ghA, ghB, and ghC modules with gC1qR. We also used single residue substitution mutants for ghA, ghB, and $\operatorname{ghC}(19,20,22)$ that allowed us to identify residues on the gClq domain that participate in the $\mathrm{C} 1 \mathrm{q}-\mathrm{gClqR}$ interaction. A number of substitution mutants: ghA-R162A, ghA-R162E, ghB-R114A, ghB-R114Q,
ghB-R163E, ghB-R163A, ghB-H117D, ghB-R129A, ghB-R129E, ghB-T175L, ghC-R156E, ghC-L170E, and ghC-H101A were tested for their interaction with $\mathrm{gClqR}$. The functional characterization of the point mutants identified an important role of $\mathrm{Arg}^{162}$ of ghA and $\mathrm{Arg}^{114}$ of ghB in the structure-function relationship involving $\mathrm{C} 1 \mathrm{q}$ and $\mathrm{gCl} \mathrm{qR}$.

It is known that at sites of inflammation, adherent monocytes start to overexpress C1q. Thus, we performed a series of qPCR experiments to assess whether $\mathrm{gC} 1 \mathrm{qR}$ expression was concomitant with $\mathrm{C} 1 \mathrm{q}$ in adherent monocytes. gC1qR was upregulated, together with $\mathrm{C} 1 \mathrm{q}$ on adherent monocytes, suggesting that both the ligand and the receptor are required under inflammatory conditions. The previously reported C1q-mediated anti-proliferative effect on T cells (25) could be reproduced qualitatively by the individual recombinant gh modules, which inhibited phytohemagglutinin (PHA)-stimulated proliferation of PBMCs. This anti-proliferative effect of gh modules was further enhanced by the addition of $\mathrm{gC1} 1 \mathrm{qR}$, suggesting that $\mathrm{gClqR}$, in conjunction with $\mathrm{Clq}$, can play an important role in modifying cellular immune responses.

\section{EXPERIMENTAL PROCEDURES}

\section{Purification of Human C1q}

C1q was purified from freshly thawed plasma, as published earlier (26). Briefly, plasma was made 5mM EDTA, pH 7.5, and centrifuged at $12,000 \times g$ to remove aggregated lipids. The plasma was then incubated with non-immune IgG coupled to CNBr-activated Sepharose (GE Healthcare, UK) for $1 \mathrm{~h}$ at $4^{\circ} \mathrm{C}$. The plasma was filtered through a sintered glass funnel, and $\mathrm{C} 1 \mathrm{q}$ bound to IgG-Sepharose was then washed extensively with $10 \mathrm{mM}$ HEPES, $140 \mathrm{mM} \mathrm{NaCl}, 0.5 \mathrm{mM}$ EDTA, and pH 7.0. C1q was eluted with $N$-cyclohexyl-3-aminopropanesulfonic acid (CAPS) buffer (100 mM CAPS, $1 \mathrm{M} \mathrm{NaCl}, 0.5 \mathrm{mM}$ EDTA, $\mathrm{pH}$ 11). The eluted $\mathrm{Clq}$ was then passed through a HiTrap Protein G column (GE Healthcare) to remove IgG contaminants and dialyzed against the washing buffer.

\section{Expression and Purification of Wild-type ghA, ghB, ghC, and Substitution Mutants}

The recombinant gh modules ghA, ghB, ghC, and their respective substitution mutants, were expressed in Escherichia coli BL21 fused to maltose-binding protein $(\mathrm{MBP})$ in their monomeric forms (18). Bacterial cells were grown in $200 \mathrm{ml}$ Luria-Bertani (LB) medium containing ampicillin $(100 \mu \mathrm{g} / \mathrm{ml})$ at $37^{\circ} \mathrm{C}$ on a shaker. Once grown to an $\mathrm{OD}_{600}$ of 0.6 , the bacterial cells were induced with $0.4 \mathrm{mM}$ isopropyl $\beta$-D-thiogalactoside (IPTG) for $3 \mathrm{~h}$ and pelleted via centrifugation ( $4500 \mathrm{rpm}$ for $15 \mathrm{~min}$ ). The cell pellet was suspended in $25 \mathrm{ml}$ of lysis buffer $[20 \mathrm{mM}$ Tris- $\mathrm{HCl} \mathrm{pH}$ 8.0, 0.5 M NaCl, $1 \mathrm{mM}$ EDTA, 0.2\% v/v Tween 20, 5\% glycerol, $0.1 \mathrm{mM}$ phenylmethylsulfonyl fluoride (PMSF), and $100 \mu \mathrm{g} / \mathrm{ml}$ lysozyme] and incubated at $4^{\circ} \mathrm{C}$ for $1 \mathrm{~h}$ on a rotatory shaker. The cells were then sonicated (SoniPrep 150) at $60 \mathrm{~Hz}$ for $30 \mathrm{~s}$ with $2 \mathrm{~min}$ interval for 10 cycles. After centrifugation (13,000 rpm for $15 \mathrm{~min}$ ), the supernatant was collected and diluted fivefold in buffer I (20 mM Tris-HCl, pH 8.0, 100 mM NaCl, 0.2\% Tween 
20, $1 \mathrm{mM}$ EDTA, and 5\% v/v glycerol) and passed through an amylose resin $15 \mathrm{ml}$ bed column (New England Biolabs). The column was previously washed with three bed volumes of buffer I followed by buffer II (buffer I without Tween 20). The protein was then eluted in $1 \mathrm{ml}$ fractions with $10 \mathrm{mM}$ maltose in buffer II.

\section{Cloning, Expression, and Purification of Human gC1qR}

Recombinant mature gC1qR (residues 74-282) (27) was expressed in E. coli BL21 ( $\lambda \mathrm{DE} 3$ ) (Life Technologies). Bacterial cells were grown in $250 \mathrm{ml}$ of $\mathrm{LB}$ medium at $37^{\circ} \mathrm{C}$ until an $\mathrm{OD}_{600}$ of 0.6 was reached and protein expression was induced with $0.5 \mathrm{mM}$ IPTG. Following another $3 \mathrm{~h}$ incubation on a shaker, bacterial culture was spun down $(4500 \mathrm{rpm}, 15 \mathrm{~min})$. The cell pellet was treated with lysis buffer (20 mM Tris $\mathrm{pH} 8.0,0.5 \mathrm{M}$ $\mathrm{NaCl}, 1 \mathrm{mM}$ EDTA, $0.2 \% \mathrm{v} / \mathrm{v}$ Tween, $5 \% \mathrm{v} / \mathrm{v}$ glycerol, and $100 \mu \mathrm{g} /$ $\mathrm{ml}$ lysozyme) and incubated for $1 \mathrm{~h}$ at $4^{\circ} \mathrm{C}$ with mild shaking. The resulting cell lysate was sonicated, as described above for gh modules. The sonicate was spun down at 13,000 rpm for $15 \mathrm{~min}$, and the collected supernatant was dialyzed for $2 \mathrm{~h}$ against $20 \mathrm{mM}$ Tris- $\mathrm{HCl}, \mathrm{pH}$ 7.5. The dialyzed protein was subjected to an ion exchange chromatography using a Q-Sepharose column (Sigma).gC1qR was step-eluted at $0.45 \mathrm{M} \mathrm{NaCl}$. Although we did not determine the oligomeric state of the recombinant $\mathrm{gClqR}$, it is likely to be a trimeric structure, based on the crystallization studies (21).

The purified fractions were passed through Pierce ${ }^{\mathrm{TM}}$ High Capacity Endotoxin Removal Resin (Thermo Fisher) to remove lipopolysaccharides (LPSs). Endotoxin levels in the protein preparations were determined using the QCL-1000 Limulus amebocyte lysate system (BioWhittaker Inc., USA). The assay was linear over a range of $0.1-1.0 \mathrm{EU} / \mathrm{ml}(10 \mathrm{EU}=1 \mathrm{ng}$ of endotoxin) and the amount of endotoxin present in the preparations was estimated to be $<4 \mathrm{pg} / \mu \mathrm{g}$ of the recombinant protein.

\section{ELISA}

Direct binding ELISA was performed to examine the interaction of $\mathrm{C} 1 \mathrm{q}$ and gh modules with gC1qR. Microtiter wells (Maxisorp, Nunc) were coated with $1 \mu \mathrm{g}$ of gC1qR (in $100 \mu \mathrm{l}$ ) in carbonate/ bicarbonate buffer, $\mathrm{pH} 9.6$, and left overnight at $4^{\circ} \mathrm{C}$. Unbound proteins were removed and the wells were blocked with $2 \% \mathrm{w} / \mathrm{v}$ BSA in PBS for $2 \mathrm{~h}$ at $37^{\circ} \mathrm{C}$. The plate was then washed three times with PBS $+0.05 \%$ Tween 20 , and then different concentrations $(2.5,1.25,0.625$, and $0.312 \mu \mathrm{g} /$ well $)$ of ghA, ghB, or ghC modules (MBP as a control protein) were diluted in calcium buffer $(50 \mathrm{mM}$ Tris- $\mathrm{HCl} \mathrm{pH} \mathrm{8.0,100} \mathrm{mM} \mathrm{NaCl}$, and $5 \mathrm{mM} \mathrm{CaCl}_{2}$ ) and added to the wells. The plate was kept first at $37^{\circ} \mathrm{C}$ for $1 \mathrm{~h}$ and then at $4^{\circ} \mathrm{C}$ for another hour. Following further washes, the bound protein was detected by anti-MBP monoclonal antibody (Sigma) (1:5000 dilution in PBS) and probed with rabbit anti-mouse IgG Horseradish peroxidase (HRP; 1:5000; Promega; \#W402b) in PBS. Color was developed using $o$-phenylenediamine dihydrochloride (OPD) substrate (Thermo-Fisher Scientific) and the plate was read at $450 \mathrm{~nm}$ using iMark Microplate Absorbance reader (Bio-Rad).

Microtiter wells were coated with different concentrations of human $\mathrm{Clq}(5,2.5,1.25$, and $0.625 \mu \mathrm{g} /$ well in $100 \mu \mathrm{l})$ in carbonate/bicarbonate buffer, $\mathrm{pH} 9.6$, and left overnight at $4^{\circ} \mathrm{C}$. Unbound proteins were removed and the wells were blocked with $2 \% \mathrm{w} / \mathrm{v} \mathrm{BSA}$ in $\mathrm{PBS}$ for $2 \mathrm{~h}$ at $37^{\circ} \mathrm{C}$. The plate was then washed three times with PBS $+0.05 \%$ Tween 20 , and then the wells were incubated with $2.5 \mu \mathrm{g}$ of gC1qR in calcium buffer (50 mM Tris- $\mathrm{HCl}, \mathrm{pH} 8.0,100 \mathrm{mM} \mathrm{NaCl}$, and $5 \mathrm{mM} \mathrm{CaCl}_{2}$ ). The plate was kept first at $37^{\circ} \mathrm{C}$ for $1 \mathrm{~h}$ and then at $4^{\circ} \mathrm{C}$ for another hour. Following further washes, bound $\mathrm{gC1qR}$ was detected by anti-gC1qR polyclonal antibody (IgG fraction; 1:5000 dilution), followed by Protein A-HRP (1:5000 dilution) conjugate. MBP was used as a negative control protein.

\section{Western Blotting}

The immunoreactivity of the recombinant gC1qR (10 $\mu \mathrm{g} / \mathrm{lane})$ was assessed by western blotting. Following a $12 \% \mathrm{v} / \mathrm{v}$ SDSPAGE gel, the protein was electrophoretically transferred onto PDVF membrane, followed by blocking for $1 \mathrm{~h}$ at room temperature with 5\% non-fat milk in PBS. Recombinant human $\mathrm{gC1qR}$ was probed with rabbit anti-human $\mathrm{gC1qR}$ polyclonal antibodies (IgG fraction; $500 \mu \mathrm{g} / \mathrm{ml}$ concentration; 1:1000 dilution) and incubated at $37^{\circ} \mathrm{C}$ for $1 \mathrm{~h}$. The membrane was washed three times in 0.02\% PBS-Tween 20, 30 min each and probed with Protein A-HRP conjugate (Sigma, 1:1000 dilution in $\mathrm{PBS}$ ) for $1 \mathrm{~h}$ at room temperature. Color was developed using 3,3'-diaminobenzidine (DAB).

Far-western blot was carried out to test the interaction of ghA, ghB, ghC, and key substitution mutants with gC1qR. Ten micrograms of each protein was run on a SDS-PAGE gel, followed by transferring and blocking as described above. Fifteen micrograms per milliliter of either the gh's modules or gC1qR was added in $10 \mathrm{ml}$ calcium buffer (20 mM Tris-HCl, pH 7.5, $5 \mathrm{mM}$ $\mathrm{CaCl}_{2}$, and $100 \mathrm{mM} \mathrm{NaCl}$ ) and incubated overnight at $37^{\circ} \mathrm{C}$. Membranes were washed and probed with either polyclonal antigC1qR or rabbit anti-MBP (Life Technologies, 1:1000) polyclonal antibodies which were diluted in $2 \% \mathrm{w} / \mathrm{v}$ non-fat milk powder in PBS and incubated for $2 \mathrm{~h}$ at $37^{\circ} \mathrm{C}$. The blots were developed as described above.

\section{Fluorescence Microscopy}

The binding of recombinant ghA, ghB, and ghC modules to gC1qR was examined microscopically using monocyte-derived human macrophages. Human PBMCs were separated from human blood from healthy volunteers (with ethical approval by the Institutional committee of Brunel University London) by Ficoll-paque (GE Healthcare) density gradient method. The separated PBMCs were suspended in complete medium (RPMI 1640, $2 \mathrm{mM}$ L-glutamine, $100 \mu \mathrm{g} / \mathrm{ml}$ Penicillin/Streptomycin, and $10 \% \mathrm{FCS}$ ). The $1 \times 10^{6}$ cells were seeded on $13 \mathrm{~mm}$ diameter cover slips and incubated for 14 days at $37^{\circ} \mathrm{C}$ in $5 \% \mathrm{CO}_{2}$ incubator.

PBMCs were treated with $10 \mu \mathrm{g}$ of individual gh modules for $1 \mathrm{~h}$ at $37^{\circ} \mathrm{C}$ in serum-free medium. MBP $(10 \mu \mathrm{g})$ was used as a negative control protein. Cells were then washed three times with PBS, fixed using $4 \%$ paraformaldehyde (PFA) for $10 \mathrm{~min}$, and then rinsed with PBS three times. The coverslips were permeabilized using a buffer containing 20mM HEPES-NaOH pH 7.4, 300mM sucrose, $50 \mathrm{mM} \mathrm{NaCl}, 3 \mathrm{mM} \mathrm{MgCl}_{2}, 0.5 \%$ Triton X-100, and $10 \%$ sodium azide for $5 \mathrm{~min}$ on ice, and then blocked with $5 \%$ FCS 
in PBS (wash buffer) for $30 \mathrm{~min}$. The slides were then incubated with mouse anti-MBP (1:500 dilution in wash buffer) and rabbit anti-gC1qR antibodies (1:100 dilution in wash buffer) for $30 \mathrm{~min}$. The slides were washed three times in wash buffer, 10 min each, and subsequently incubated with secondary antibodies: Alexa Fluor 647 conjugated donkey-anti-mouse antibody (Abcam; Cat: ab150111) 1:500 dilution in wash buffer and Alexa Fluor 488 conjugated goat anti-rabbit antibody (Abcam; Cat: ab150077) 1:500 dilution in wash buffer for $30 \mathrm{~min}$. To stain the nucleus, Hoechst 33342 (Invitrogen, Cat: H3570 at 1:10,000 dilution) was used. The slides were then washed three times in the wash buffer 10 min each, mounted using Citifluor anti-fade (Citifluor, UK) and observed under a Leica DM4000 Fluorescent microscope using Leica Application Suite Software. In the merged images, the Alexa Fluor 647 color was set to red.

\section{Quantitative RT-PCR}

Whole blood $(50 \mathrm{ml})$ was taken from healthy volunteers and 2 units/ml of heparin sodium (product details - PL 29931/015) (Wockhardt), was added to prevent blood clotting. Blood was then diluted with an equal volume of RPMI 1640. To isolate monocytes, blood in RPMI 1640 was separated on a Ficol column (Ficol-Plaque Plus, GE healthcare) by centrifugation at $2000 \mathrm{rpm}$ for $16 \mathrm{~min}$ at room temperature. The top layer was removed and PBMCs interphase layer was carefully removed. An equal volume of RPMI 1640 was then added and the cells were pelleted by centrifugation at $1500 \mathrm{rpm}$ for $10 \mathrm{~min}$ at room temperature. Cells were then re-suspended in $50 \mathrm{ml}$ of RPMI 1640 and the cell concentration was determined using a hemocytometer (total yield $7 \times 10^{7}$ cells).

Then, $5 \times 10^{6}$ cells were added to each tissue culture well in a 24-well plate in $5 \mathrm{ml}$ of RPMI 1640 containing 10\% FCS, $100 \mu \mathrm{g} / \mathrm{ml}$ penicillin-streptomycin, and $2 \mathrm{mM}$ L-glutamine, and incubated at $37^{\circ} \mathrm{C}$ with $5 \% \mathrm{CO}_{2} \mathrm{v} / \mathrm{v}$ atmosphere and left to adhere. Cells were then harvested at the following time points of incubation for adherence: 2 h, 24 h, 48 h, 72 h, 5 days, and 7 days. A similar experiment was also set up with the addition of $20 \mathrm{ng} / \mu \mathrm{l}$ of LPS (Salmonella typhimurium, Sigma-Aldrich). Adherent cells, with or without LPS, from each time point were harvested by removing the media from the plate and incubating cells in RPMI 1640 containing $0.025 \%$ trypsin $/ 0.01 \%$ EDTA for $5 \mathrm{~min}$ at $37^{\circ} \mathrm{C}$. Cells were removed using a cell scraper and an equal volume of RPMI 1640 containing 10\% FCS was added to the harvested cells. Cells were pelleted by centrifugation at $1500 \mathrm{rpm}$ for $10 \mathrm{~min}$ at room temperature and stored at $-80^{\circ} \mathrm{C}$ until RNA extraction was carried out.

Total RNA was extracted using the GenElute Mammalian Total RNA Purification Kit (Sigma-Aldrich). Samples were then treated with DNase I (Sigma-Aldrich) to remove any contaminating DNA followed by heating at $70^{\circ} \mathrm{C}$ for $10 \mathrm{~min}$ to inactivate both DNase I and RNase, and then chilled on ice. The amount of total RNA was measured by determining the absorbance at $260 \mathrm{~nm}$ using the NanoDrop 2000/2000c (Thermo-Fisher Scientific) and the purity of the RNA was assessed using the ratio of absorbance at 260 and $280 \mathrm{~nm}$. cDNA was synthesized using High Capacity RNA to cDNA Kit (Applied Biosystems) using $2 \mu \mathrm{g}$ of total RNA.
Primer sequences were designed using the nucleotide Basic Local Alignment Search Tool and Primer (BLAST, http://blast. ncbi.nlm.nih.gov/Blast.cgi). The following primers were used: for $18 \mathrm{~S}$ rRNA gene (endogenous control): forward (5'-ATG GCCGTTCTTAGTTGGTG-3'), reverse (5'-CGCTGAGCCAGT CAGTGTAG-3'); for C1q C chain gene: forward (5'-CAAA GGGCAGAAGGGAGAAC- $3^{\prime}$ ), reverse (5'-ATCTGATCAGGC TGTTGGGT-3'); and for gC1qR gene: forward (5'-AACAA CAGCATCCCACCAAC- $\left.3^{\prime}\right)$, reverse (5'-AGATGTCACTCTCA GCCTCG-3').

PCR was performed on all samples in order to assess the quality of cDNA. The qPCR reactions, performed for measuring the expression level of $\mathrm{Clq}$ and $\mathrm{gC1} 1 \mathrm{qR}$, consisted of $5 \mu \mathrm{l}$ Power SYBR Green MasterMix (Applied Biosystems), 75nM of forward and reverse primer, $500 \mathrm{ng}$ template cDNA in a $10 \mu \mathrm{l}$ final volume, using a 7900HT Fast Real-Time PCR System (Applied Biosystems). The initial steps were $2 \mathrm{~min}$ incubation at $50^{\circ} \mathrm{C}$, followed by $10 \mathrm{~min}$ incubation at $95^{\circ} \mathrm{C}$. The template was then amplified for 40 cycles under these conditions: $15 \mathrm{~s}$ at $95^{\circ} \mathrm{C}$ and $1 \mathrm{~min}$ at $60^{\circ} \mathrm{C}$. Samples were normalized using the expression of human $18 \mathrm{~S}$ rRNA. Data were analyzed using the Relative Quantification (RQ) Manager Version 1.2.1 (Applied Biosystems). Cycle threshold (Ct) values for each target gene were calculated and the relative expression was calculated using the RQ value via the formula: $\mathrm{RQ}=2^{-\Delta \Delta \mathrm{Ct}}$ for each target gene, and comparing relative expression with that of the $18 \mathrm{~S}$ rRNA constitutive gene product. Assays were conducted twice in triplicate. Statistical analysis was performed using GraphPad Prism version 6.0 (GraphPad Software). An unpaired two-side $t$-test was used to compare the means of the expressed targets of the time points analyzed, using the $2 \mathrm{~h}$ time point as the calibrator. $p$ Values were computed, and graphs compiled and analyzed.

\section{Cell Proliferation Assay}

PBMCs were re-suspended in serum-free medium containing RPMI 1640, Penicillin/Streptomycin and Sodium Pyruvate, and stimulated with PHA (Sigma; 11249738001) at a concentration of $1 \mu \mathrm{g} / \mathrm{ml}$ and $1 \times 10^{5}$ cells $(100 \mu \mathrm{l})$ were aliquoted per well in a 96-well tissue culture plate. Next, the cells were treated with $20 \mu \mathrm{g} / \mathrm{ml}$ of ghA, ghB, ghC, or gC1qR in their respective wells. Different concentrations of $\mathrm{gClqR}(1.25,2.5,5$, and $10 \mu \mathrm{g})$ were also coincubated with $20 \mu \mathrm{g}$ each of gh modules. At the $72 \mathrm{~h}$ time point, ${ }^{3} \mathrm{H}$-methy thymidine (MP Biomedicals, USA) was added and the plate was pulsed for $16 \mathrm{~h}$. Cells were subsequently harvested using a semi-automated cell harvester and the amount of ${ }^{3} \mathrm{H}$-thymidine incorporated into DNA was measured using a liquid scintillation counter. Each experiment was conducted in triplicates.

\section{RESULTS}

\section{Expression and Purification of Recombinant Human gC1qR in E. coli under Bacteriophage T7 Promoter}

Recombinant expression of human $\mathrm{gClqR}$ has been previously reported in E. coli as fusion to Glutathione-S-transferase (28). 
Here, we expressed human $\mathrm{gC1qR}$ without any fusion partner under a strong bacteriophage T7 promoter. E. coli BL21 ( $\lambda \mathrm{DE} 3)$ cells, containing the gC1qR construct, expressed a $\sim 33 \mathrm{kDa}$ protein following IPTG induction, compared to the uninduced cells (Figure 1A). The overexpressed protein appeared in the soluble fraction following cell lysis and sonication. Recombinant gC1qR was subsequently purified using Q-Sepharose. It was step-eluted at $0.45 \mathrm{M} \mathrm{NaCl}$ and appeared as a single band on SDS-PAGE under reducing conditions. The immunoreactivity of the purified recombinant $\mathrm{gC} 1 \mathrm{qR}$ was confirmed by western blot using anti-gC1qR polyclonal antibodies that were raised against native human gC1qR (Figure 1B).

\section{Recombinant gC1qR Binds Differentially to the Three Globular Head Modules of Human C1q}

The recombinant gh modules ghA, ghB, ghC (Figure 2A) and their substitution mutants (Figures 2B-D) were expressed as $\mathrm{MBP}$ fusion proteins and purified on amylose resin. $\mathrm{gC1qR}$ bound full-length $\mathrm{C} 1 \mathrm{q}$ in a dose-dependent manner (Figure 3A). When different concentrations of the ghA, ghB, and ghC modules were allowed to bind to a constant concentration of gC1qR, all modules bound to $\mathrm{gClqR}$ independently in a dose-dependent manner (Figure 3B). ghA showed greater binding at $2.5 \mu \mathrm{g}$ when compared with the other two modules, which is consistent with previous findings (29), which implicated ghA to be the most important gh region in the $\mathrm{C} 1 \mathrm{q}-\mathrm{gCl} \mathrm{qR}$ interaction. To confirm the ELISA results, far-western blot was performed using recombinant $\mathrm{gClqR}$, ghA, ghB, and ghC proteins. Transferring $\mathrm{gC1qR}$ onto PDVF membrane and probing with gh modules revealed independent binding of ghA, ghB, and ghC to $\mathrm{gClqR}$ (Figure 3C). Similarly, ghA, ghB, or ghC transferred onto PDVF membrane and individually probed with gC1qR confirmed the interaction (data not included) that each gh module binds specifically to $\mathrm{gClqR}$ irrespective of their immobilized orientation on the membrane.

\section{$\operatorname{Arg}^{\mathrm{A} 162}$ Is Crucial for C1q-gC1qR Interaction}

Using ELISA, we examined the ability of gC1qR to interact with recombinant ghA and its single residue substitution mutants, ghA-R162A (i.e., $\operatorname{Arg}^{\mathrm{A} 162} \mathrm{Ala}$ ) and R162E. Different amounts of $\mathrm{gC1qR}$ were coated on microtiter wells and incubated with wildtype ghA, R162A and R162E. As shown in Figure 4A, the substitution of $\mathrm{Arg}^{\mathrm{Al} 62}$ to Ala (R162A) resulted in up to $70 \%$ reduction in $\mathrm{gClqR}$ binding at $1 \mu \mathrm{g} / \mathrm{ml}$ concentration, with respect to the background binding to MBP control protein. Substitution of $\operatorname{Arg}^{\mathrm{A} 162}$ with Glu (R162E) resulted in similar abrogation of binding when compared to wild-type ghA. To further confirm these observations, we carried out a far western blot (Figure 4D). Thus, $15 \mu \mathrm{g}$ of $\mathrm{gC} 1 \mathrm{qR}$ was transferred onto a PDVF membrane and probed with $10 \mu \mathrm{g}$ each of ghA, R162E and R162A. Figure 4D shows a clear band for wild-type ghA. However, probing with the mutants revealed a very faint band for R162A while no band could be detected on the blot in the case of R162E.

\section{Arginine and Histidine Residues within the ghB Module Appear Important for Stabilizing C1q-gC1qR Interaction}

The ability of ghB and its single residue substitution mutants (R114Q, R114A, R163A, R163E, T175L, R129A, R129E, and $\mathrm{H} 117 \mathrm{D})$ to bind microtiter-coated $\mathrm{gClqR}$ was examined using ELISA. The mutant $\mathrm{Arg}^{\mathrm{B} 114}$ to $\mathrm{Gln}$ (R114Q) bound better to gC1qR than the wild-type ghB (Figure 4B), suggesting that replacing a charged (polar) residue with an uncharged residue can strengthen binding between the two proteins. Substituting $\operatorname{Arg}^{\mathrm{B} 114}$ with Ala,

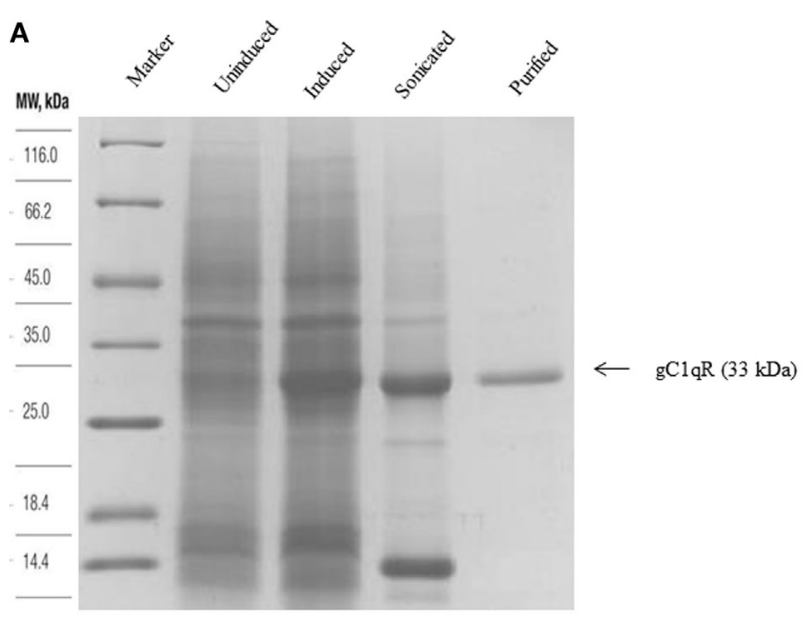

B

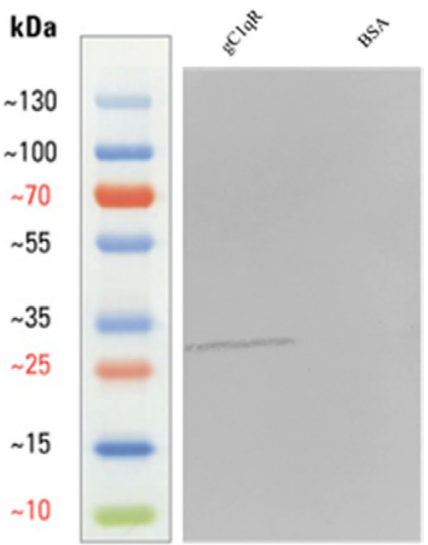

FIGURE 1 | (A) Expression and purification of recombinant gC1qR. Twelve percent (v/v) SDS-PAGE under reducing conditions. E. coli BL21 ( $\lambda D E 3)$ strain, transformed with plasmid T7-gC1qR and induced with IPTG, overexpressed a $\sim 33 \mathrm{kDa}$ protein (induced) as compared to uninduced cells. Following lysis and sonication of the bacterial cells, the overexpressed gC1qR appeared in the soluble fraction sonicate, which was further purified on a Q-Sepharose column. (B) Western blotting to show immunoreactivity of recombinant gC1qR: $10 \mu \mathrm{g}$ of recombinant gC1qR protein was run on a $12 \% \mathrm{~V} / \mathrm{V}$ gel and transferred onto a nitrocellulose membrane, which was probed with anti-gC1qR polyclonal antibody. BSA was used as a negative control protein. 

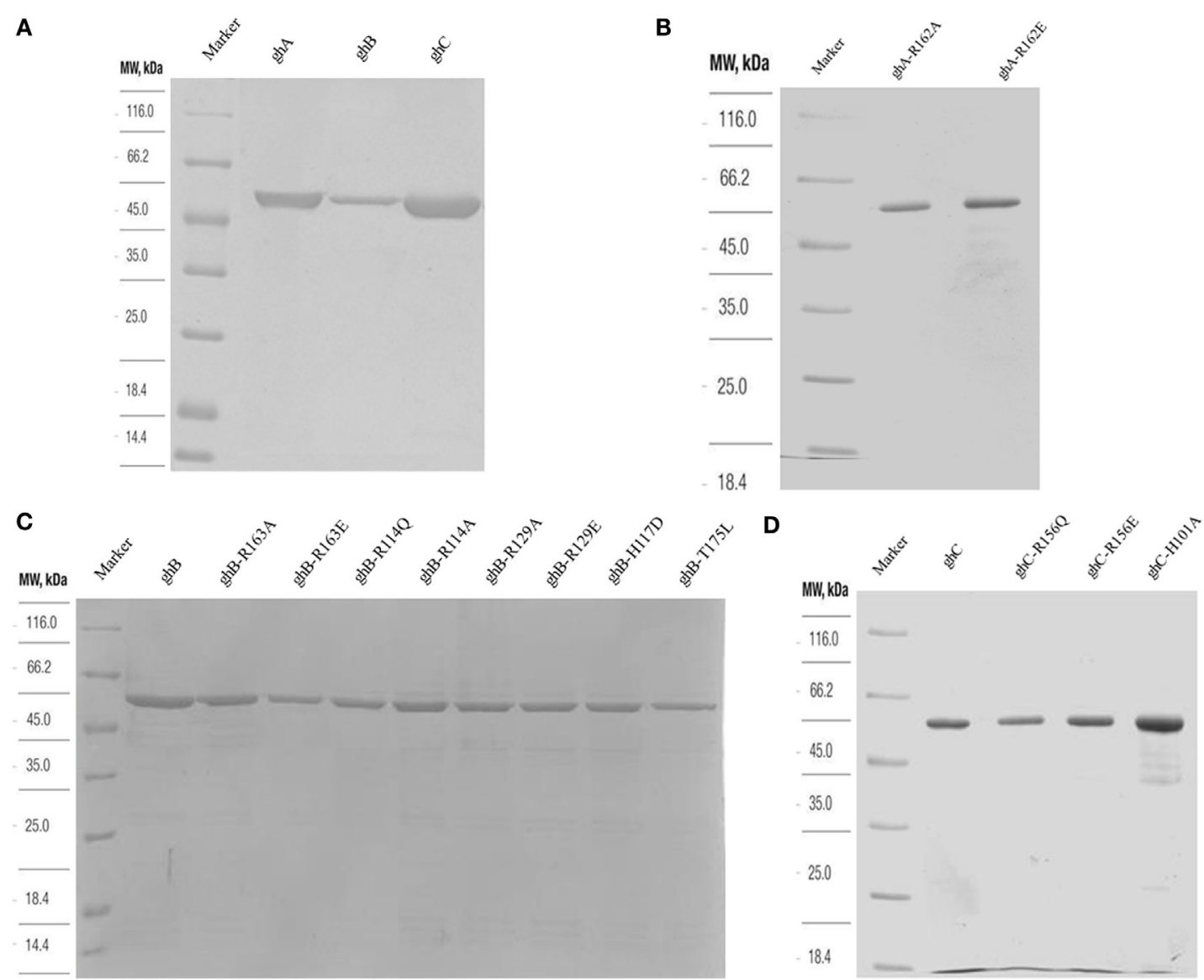

FIGURE 2 | SDS-PAGE (12\% w/v) under reducing conditions of purified fusion proteins following affinity chromatography. MBP fusion proteins containing wild type and mutant globular head modules were purified using an amylose resin column (A). Purified ghA, ghB and ghC (B) purified substitution mutants of ghA module; (C) purified mutants of ghB module, R163A, R163E, R114Q, R114A, R129A, R129E, H117D, and T175L; (D) purified ghC, R156Q, R156E, and H101A.

however, was not comparable with R114Q (Figure 4B). Out of all the ghB mutants, R114A, R129E, R163E, and H117D showed considerable reduction in binding. Thus, substituting arginine with glutamine had an adverse effect on the ghB-gC1qR interaction. Substituting His to Asp reduced ghB affinity for gC1qR by nearly $60 \%$, which suggests that $\mathrm{His}^{\mathrm{B} 117}$ is very important for $\mathrm{gClqR}$ binding. When comparing all the ghB substitution mutants, it was evident that the most significant effect was caused by the substitution of arginine to glutamine, suggesting that $\operatorname{Arg}^{B 163}$ is crucial for gC1qR binding to $\mathrm{Clq}$ (Figure 4B). Similar observations were noted for the ghC mutants (Figure 4C).

\section{Microscopy Studies}

Since we established that ghA, ghB, and ghC individually bind to $\mathrm{gC1qR}$, we performed microscopic studies to determine whether the gh's of $\mathrm{Clq}$ can colocalize with $\mathrm{gClqR}$ on the surface of PBMCs. We first verified the interaction by identifying $\mathrm{gClqR}$ on the surface using polyclonal antibodies against $\mathrm{gClqR}(\mathrm{gClqR}$ in Figure 5). Incubation of the gh modules and probing with anti-MBP monoclonal antibodies showed the gh's bound on the surface of PBMCS with partial colocalization to gC1qR (Figure 5, arrows in merged images).

\section{Transcriptional Expression of gC1qR and C1q in Adherent Monocytes}

To examine a possible correlation between the temporal pattern of expression of $\mathrm{C1q}$ and $\mathrm{gC1qR}, \mathrm{qPCR}$ analysis was performed in view of the fact that adherent monocytes upregulate $\mathrm{Clq}$ expression, a situation that mimics inflammation. In addition, the expression of $\mathrm{C} 1 \mathrm{q}$ and $\mathrm{gClqR}$ in the adherent monocytes was also assessed with and without LPS challenge (acting as a proinflammatory stimulus). C1q-RNA expression increased markedly in monocytes during adherence, peaking at $72 \mathrm{~h}$ with a $\log _{10}$ 3.5-fold difference compared to $2 \mathrm{~h}$ after adherence (Figure 6A). In contrast, incubation with LPS had a suppressive effect on $\mathrm{C1q}$ expression. There was also an increase in the $\mathrm{gClqR}$ expression during monocyte adherence, with the pattern of expression appearing to be biphasic in nature with the peaks observed at 24 and $72 \mathrm{~h}$ (Figure 6B). In contrast to C1q, the presence of LPS elevated the expression of $\mathrm{gClqR}$, peaking at $24 \mathrm{~h}$ adherence, 

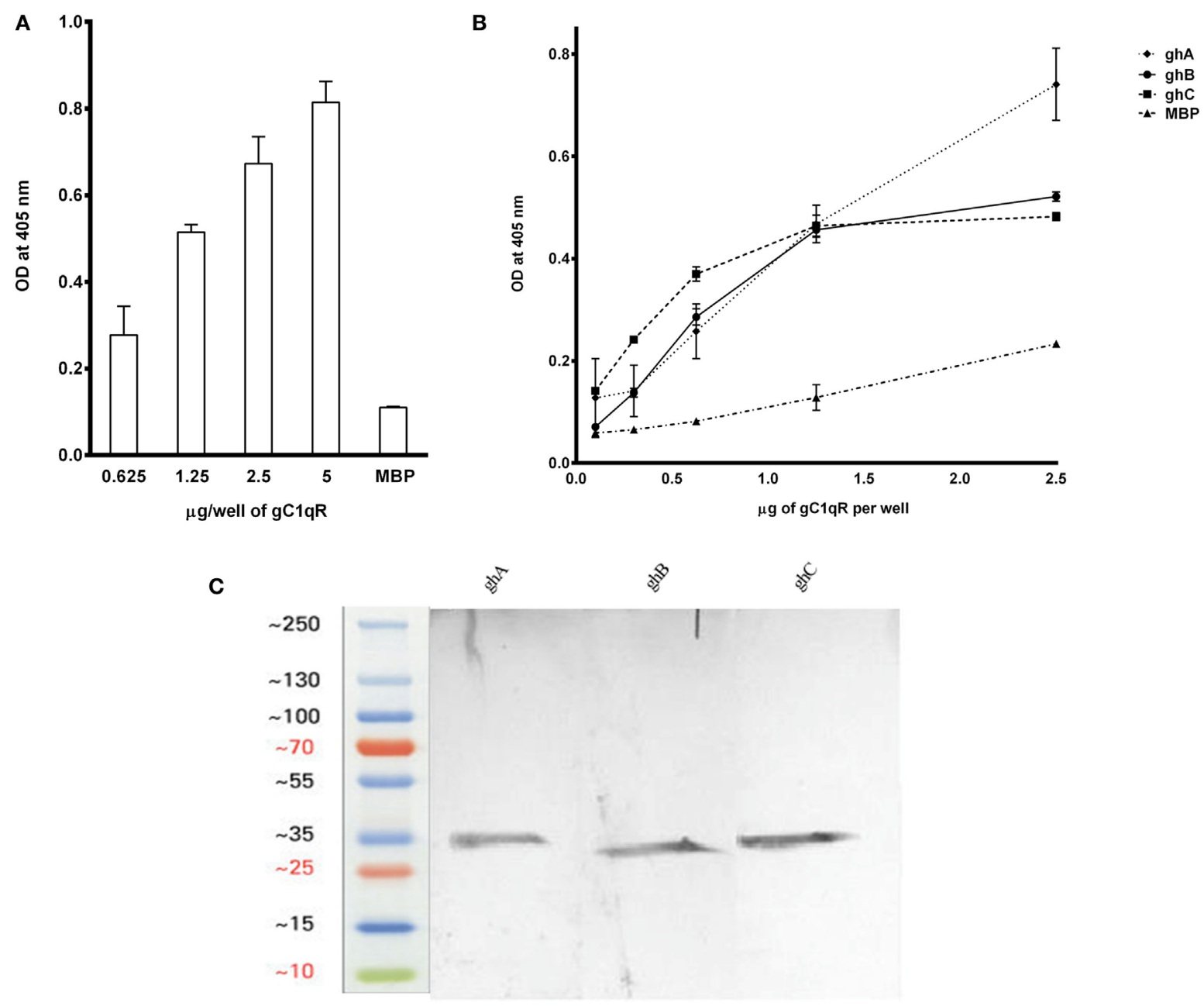

FIGURE 3 | (A) ELISA to show binding of gC1qR to C1q: microtiter wells, coated with different concentrations of human C1q $(5,2.5,1.25$, and $0.625 \mu \mathrm{g} /$ well), were incubated with $2.5 \mu \mathrm{g}$ of gC1 $\mathrm{gR}$. Bound gC1qR was detected by anti-gC1qR polyclonal antibody followed by Protein A-HRP conjugate. MBP was used as a negative control protein. (B) ELISA to assess interaction of gC1qR with ghA, ghB, and ghC modules. gC1qR (1 $\mu \mathrm{g} /$ well in $100 \mu$ l) was coated on microtiter wells and then incubated with various concentrations of wild type of ghA, ghB, and ghC. MBP was used as a negative control. Following washing, bound protein was detected using anti-MBP monoclonal antibody and goat anti-mouse lgG HRP conjugate. (C) Far-western blot analysis to show ghA, ghB, and ghC binding to gC1qR: $15 \mu \mathrm{g}$ of gC1qR was first run on the SDS-PAGE under reducing conditions, transferred onto a PDVF membrane and then probed with $10 \mu \mathrm{g}$ each of ghA, ghB, and ghC. Lanes 1 through 3 show interaction of gC1qR with ghA, ghB, and ghC, respectively.

more than twice the level observed without LPS. These results are consistent with an earlier study, showing enhancement of gC1qR surface expression on endothelial cells after $24 \mathrm{~h}$ (30). However, LPS seems to cause enhancement of gC1qR expression rather than inhibition, unlike $\mathrm{Clq}$ (Figure 6A), suggesting that $\mathrm{gClqR}$ on its own may have a regulatory role in LPS-mediated inflammation.

\section{ghA, ghB, ghC, and gC1qR Inhibit PHA-Stimulated Proliferation of PBMCs}

Since $\mathrm{C1q}$ is known to have anti-proliferative effect on $\mathrm{T}$ cells (25), we examined if this inhibition is mediated through the $\mathrm{gClq}$ domain. ghA, ghB, and ghC individually were able to inhibit PHAstimulated proliferation of PBMCs (Figure 7A), as measured by thymidine uptake. The gh modules inhibited proliferation by $>$ threefold when compared to PBMCs stimulated with PHA alone and MBP control. Next, we sought to determine whether the addition of different concentration of $\mathrm{gClqR}$ to a fixed gh concentration would further inhibit proliferation. Figure 7B shows an inhibitory dose response for each gh module with the addition of $\mathrm{gClqR}$ at different concentrations. The addition of $1.25 \mu \mathrm{g}$ of $\mathrm{gClqR}$ increased ghA and ghC mediated anti-proliferative effects by $40 \%$ (Figure 7 B).

\section{DISCUSSION}

$\mathrm{C} 1 \mathrm{q}$, as a charge pattern recognition protein, is able to bind to a range of self and non-self-ligands through its heterotrimeric 


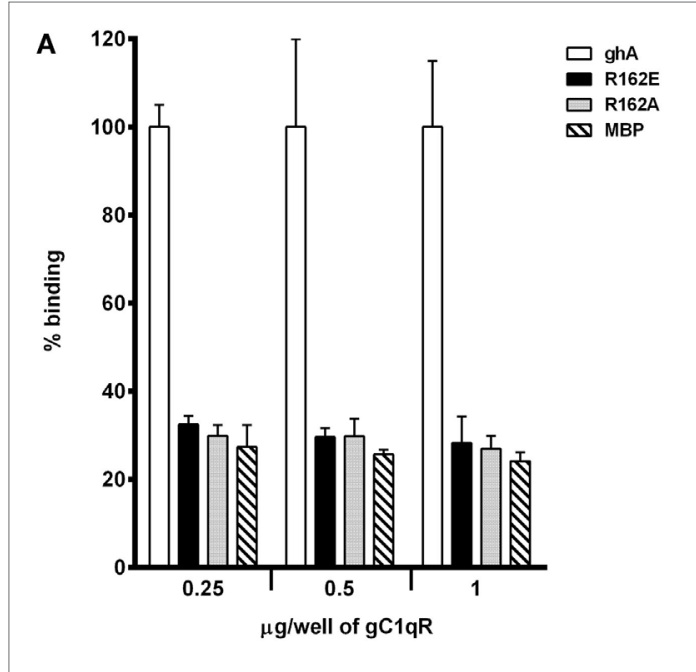

C

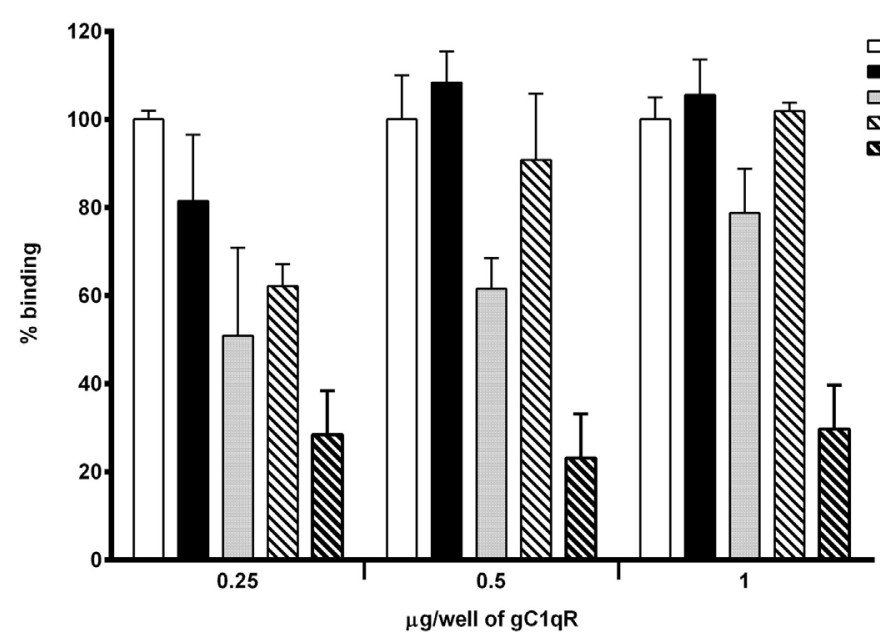

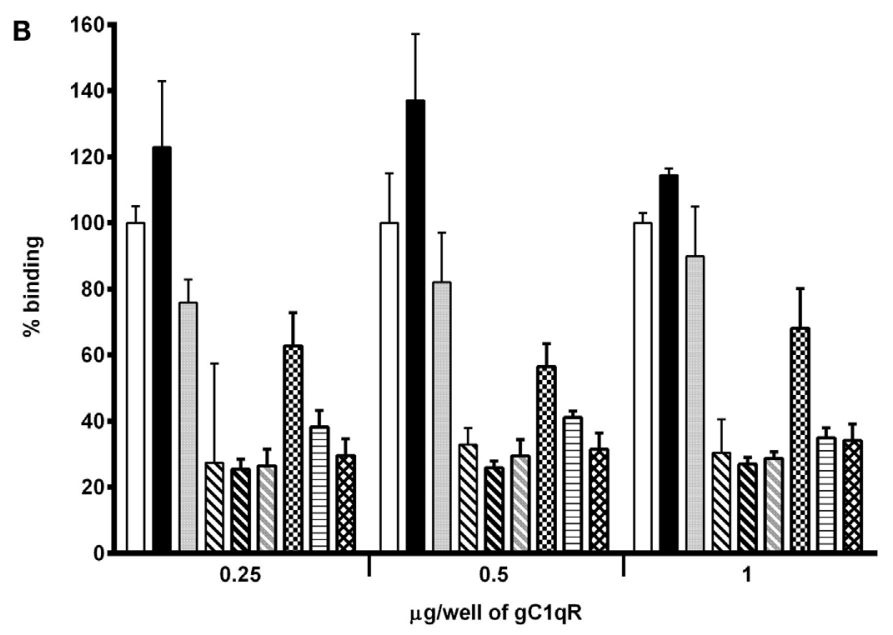

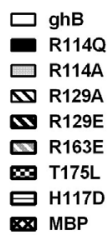

D

FIGURE 4 | ELISA to assess interaction between gC1qR and gh substitution mutants. Microtiter wells were coated with different quantities (0.25, 0.5, and $1 \mu \mathrm{g} /$ well) of gC1qR. After blocking and washing, the wells were incubated with $2.5 \mu \mathrm{g} /$ well of (A) ghA, R162A and R162E; (B) ghB, R114A, R114Q, R163A, R163E, R129A, R129E, T175L, and H117D; and (C) ghC, for 90 min at $37^{\circ} \mathrm{C}$ and 90 min at $4^{\circ} \mathrm{C}$. Bound proteins were detected with anti-MBP monoclonal antibody followed by goat anti-mouse lgG-HRP conjugate. Data are representative of three experiments. (D) Ligand blot to show binding of ghA mutants R162A and R162E to gC1qR: PVDF membrane strips containing gC1qR were reacted with ghA, R162A and R162E, and then probed with anti-MBP monoclonal antibody followed by goat anti-mouse lgG-HRP.

gC1q domain $(5,31)$. The $\mathrm{gClq}$ domain is also found in a range of non-complement proteins $(22,32,33)$, including collagen VIII, precerebellin, and multimerin (2, 32-37). The crystal structure analysis of the gC1q domain shows a sphere-shaped, heterotrimeric arrangement with the $\mathrm{N}$ - and $\mathrm{C}$-terminal ends of each domain residing at the base of the trimer (5). The crystal structure has also identified an exposed $\mathrm{Ca}^{2+}$ ion located at the apex; this has been considered important in the binding of $\mathrm{gClq}$ to its ligands.

Out of several candidate receptors for $\mathrm{Clq}$, calreticulin (cC1qR) binds to the collagen region of $\mathrm{Clq}$, while $\mathrm{gClqR}$ interacts with the gC1q domain $(2,13)$. However, the nature and the context of interaction between $\mathrm{Clq}$ and $\mathrm{gClqR}$ have not been examined. Previous studies, using ligand blot analysis with $\mathrm{C} 1 \mathrm{q}$ run under reducing conditions, have shown that $\mathrm{gClqR}$ binds predominantly to the A chain and moderately to the $\mathrm{C}$ chain of $\mathrm{C} 1 \mathrm{q}$ with the A chain Arg residue at positions 162 being critical for binding (28). The availability of the recombinant forms of ghA, ghB, and ghC (18) and their substitution mutants (22) gave us with the opportunity to fully explore the gC1q-gC1qR interaction.

Previous studies have shown that $\mathrm{gClqR}$ inhibits aggregated IgG-mediated complement activation by binding to the gC1q site on $\mathrm{Clq}$, thereby preventing IgG from binding to the gh's (28), suggesting that the binding sites for $\mathrm{gCl} \mathrm{qR}$ and $\mathrm{IgG}$ on $\mathrm{C} 1 \mathrm{q}$ may be identical or at least overlapping. It has also been shown that one of the IgG binding sites resides on $\mathrm{Arg}^{162}$ of the A chain (38), consistent with the mutational studies where the mutant R162E showed reduced the ability of C1q to bind to IgG by $35 \%$ (22). 


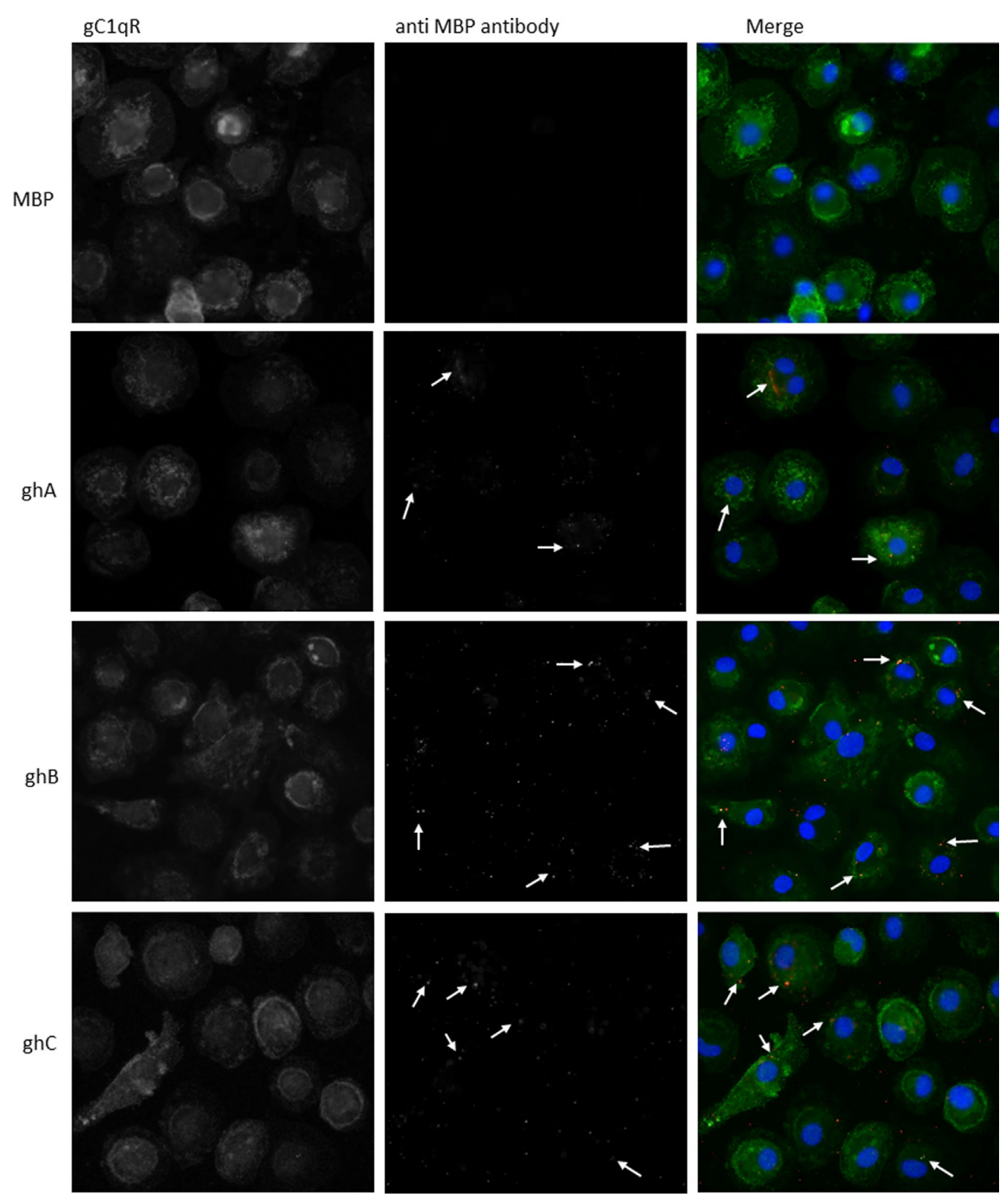

FIGURE 5 | Interaction of ghA, ghB, and ghC with monocyte/macrophages. PMBCs $\left(1 \times 10^{6}\right)$ were seeded on 13 mm coverslips and incubated in complete RPMl 1640 medium for 2 weeks at $37^{\circ} \mathrm{C}$ in $5 \% \mathrm{CO}_{2}$ incubator. Cells were treated with $10 \mu \mathrm{g}$ of each globular head module and incubated with serum-free RPMl 1640 medium for $1 \mathrm{~h}$ at $37^{\circ} \mathrm{C}$. After washing with PBS, cells were fixed with $4 \%$ PFA, permeabilzed with Triton X-100, and probed with anti-gC1qR polyclonal antibody and anti-MBP monoclonal antibody to reveal gC1qR and bound globular head modules, respectively. Cells were washed and treated with Alexa Fluor 488 conjugated secondary goat anti-rabbit antibody and Alexa Fluor 647 conjugated secondary donkey anti-mouse antibody and the nucleus was stained with Hoechst 33342. Cells were then examined under Leica fluorescence microscope with 40x magnification. In the merged images gC1qR is green; globular heads are red; and nucleus is blue. Arrows point to bound globular heads with colocalization of globular heads and gC1qR seen in orange in the merged images. Scale bars: $10 \mu \mathrm{m}$.

The importance of arginine residues in the ligand recognition of $\mathrm{gClq}$ domain is consistent with the observation in this study (Figure 3B). Ghebrehiwet et al. have previously shown that the $\mathrm{Arg}^{162}$ in C1q A chain is significant in $\mathrm{gClqR}$ binding (39). A peptide corresponding to the A chain with the Arg residue at position 162 substituted to Glu showed no binding to gC1qR. It has also been noted that residues $154-165$ of the A chain are implicated in IgG binding (38), and inhibition studies have demonstrated that forming a complex between $\mathrm{gClqR}$ and $\mathrm{Clq}$ prevented $\mathrm{Clq}$ binding to SRBCs, and hence, complement activation. These data are consistent with Figure 4A, which shows that substitution of the arginine residue in ghA reduces its binding to $\mathrm{gClqR}$ considerably. We further examined the contributions of $\operatorname{Arg}^{114}$, $\mathrm{Arg}^{163}$, and $\mathrm{His}^{117}$ (of ghB) and $\mathrm{Arg}^{156}$ (of ghC) to the C1q-gClqR 


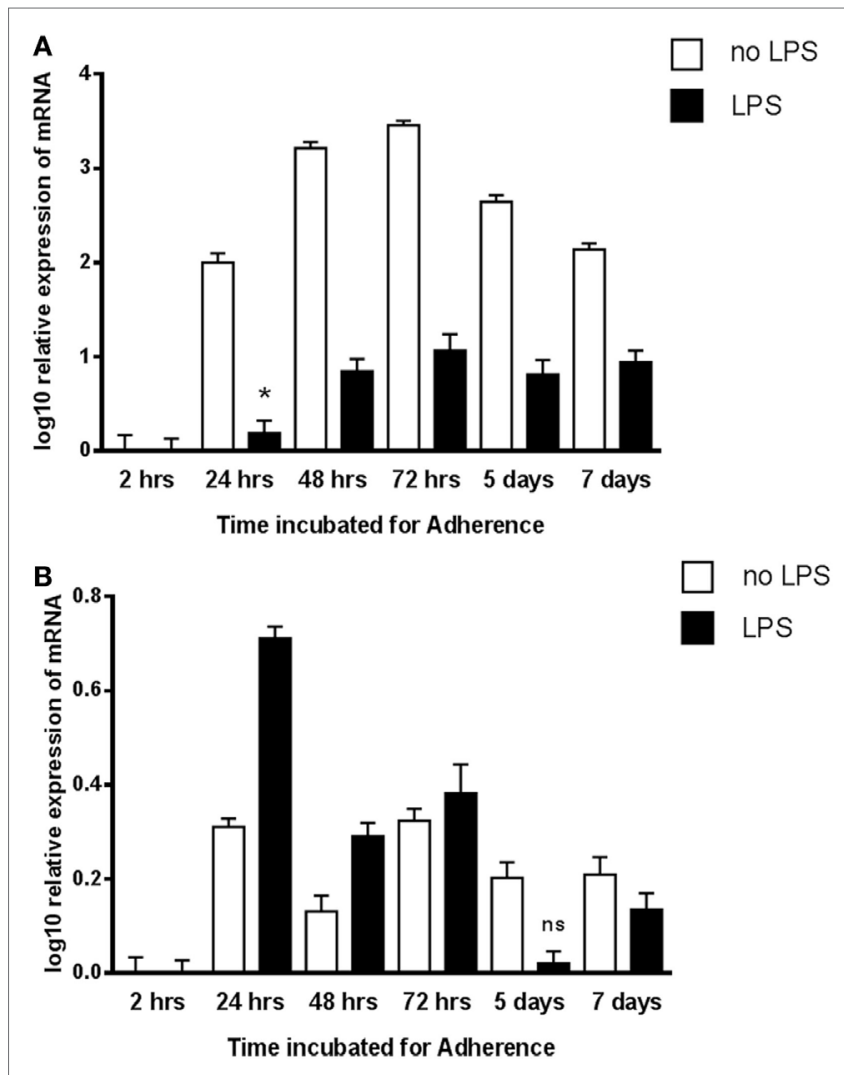

FIGURE 6 | Expression of C1q (A) and gC1qR (B) by adherent human monocytes in vitro. The expression of $\mathrm{C} 1 \mathrm{q}$ and $\mathrm{gC} 1 \mathrm{qR}$ was measured using real-time qPCR and the data were normalized via $18 \mathrm{~S}$ rRNA gene expression as a control. Relative expression $(R Q)$ was calculated by using the $2 \mathrm{~h}$ time point as the calibrator. The $R Q$ value was calculated using the formula: $R Q=2^{-\Delta \Delta C t}$. Assays were conducted twice in triplicates. Error bars represent \pm SEM. A two-side $t$-test was performed on the data. All samples showed significant expression compared to the calibrator ( $p \leq 0.01)$, except where noted: ${ }^{*} 0.01<p<0.05$; ns: not significant $(p \geq 0.05)$. LPS was added to cultures at a $20 \mathrm{ng} / \mu \mathrm{l}$ concentration.

interaction by substituting them with either neutral or negatively charged residues. Thus, the substitution of Arg to glutamine at amino acid 114 position of the B chain showed a much better binding to $\mathrm{gClqR}$ than the wild-type ghB. The observation that a substitution mutant interacts better than the wild type is of great interest, offering an opportunity to neutralize the involvement of gC1qR in infection and inflammation. Experiments involving chemical modification have shown $\mathrm{Arg}^{11}$ of the $\mathrm{B}$ chain to be an important residue in IgG binding (38).

The qPCR-based mRNA expression studies appeared to suggest that both $\mathrm{C} 1 \mathrm{q}$ and $\mathrm{gClqR}$ are upregulated in adherent monocytes in a biphasic manner. It is likely that the two proteins are coexpressed under pro-inflammatory conditions and can regulate each other's functions, or may have distinct functions by recognizing unique self and non-self-molecular targets. When LPS was used in the assay, the expression of C1q was downregulated, but $\mathrm{gCl} 1 \mathrm{qR}$ levels were upregulated, suggesting that $\mathrm{Clq}$ and gC1qR may have distinct roles in LPS-mediated immune response that are independent of each other.

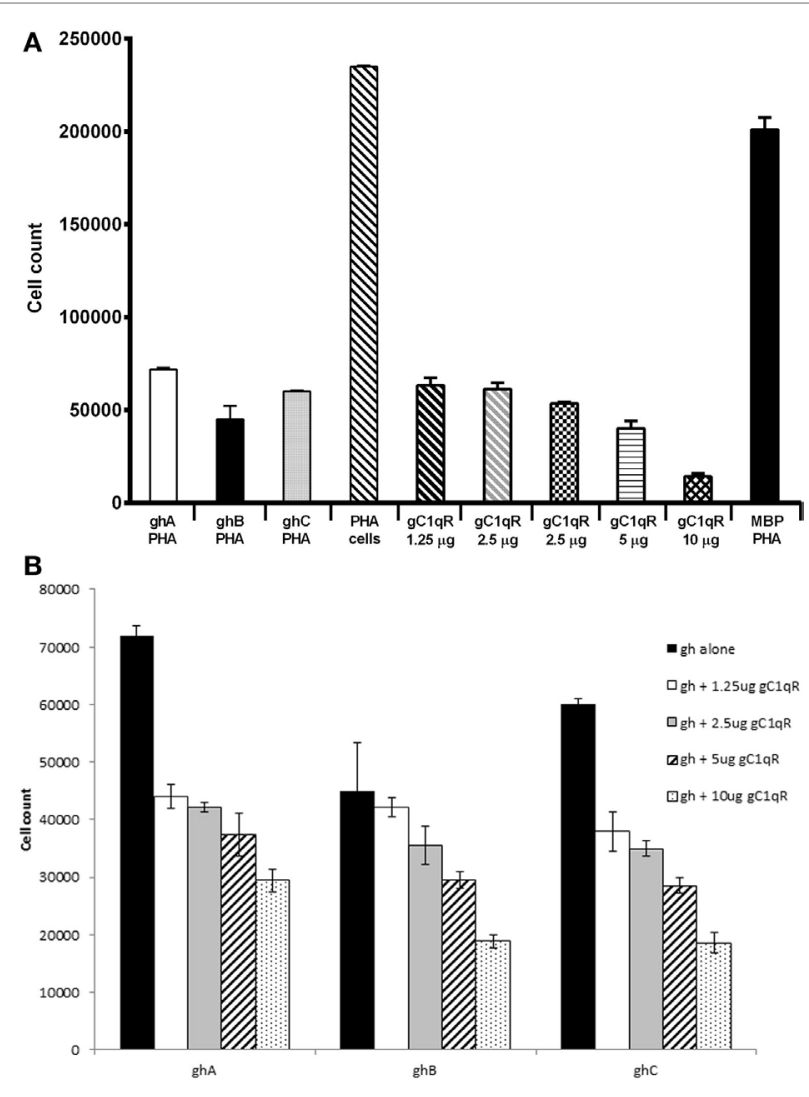

FIGURE 7 | Anti-proliferative effects of ghA, ghB, and ghC modules. Human PBMCs from healthy individuals were stimulated with PHA $(1 \mu \mathrm{g} / \mathrm{ml})$ for 3 days with or without recombinant $\mathrm{gC} 1 \mathrm{qR}(1.25,2.5,5,10$, and $20 \mu \mathrm{g} /$ $\mathrm{ml})$, ghA, ghB, or ghC $(20 \mu \mathrm{g} / \mathrm{ml})$ followed by a $16 \mathrm{~h}$ pulse in the presence of tritiated methyl thymidine $\left(\left[{ }^{3} \mathrm{H}\right] \mathrm{TdR}\right)$. Each experiment was carried out in triplicates. (A) Each of ghA, ghB, ghC, and gC1qR inhibited PHA-stimulated proliferation of PBMCs; (B) ghA, ghB, and ghC coincubated with gC1qR inhibit PHA-stimulated proliferation of PBMCs.

Since $\mathrm{Clq}$ is known to exert an anti-proliferative effect on T cells (25), it was of interest to examine if individual gh modules were also anti-proliferative and if the addition of $\mathrm{gClqR}$ in the assay could modulate this effect. Here, we show that ghA, ghB, and ghC modules also possess anti-proliferative properties of $\mathrm{C} 1 \mathrm{q}$ (Figure 7). gC1qR had an additive effect on the anti-proliferative effects of gh modules in a dose-dependent manner (Figure 7A). The engagement of $\mathrm{Clq}$ with $\mathrm{gClqR}$, expressed on $\mathrm{CD}^{+}$and $\mathrm{CD}^{+} \mathrm{T}$ cells, is known to suppress cell proliferation (25). Therefore, further attenuation of cell proliferation by $\mathrm{gClqR}$ is likely to be mutually beneficial for the immune regulation. Previously, it was thought that the "full-length" gC1qR (residues 1-282) was mostly resident in the mitochondria, which is then cleaved off to release the "mature form" (residues 74-282) expressed on the cell surface (16). However, subsequent studies have shown that the membrane associated-form is, in fact, the full-length $\mathrm{gClqR}$ from which the mature form consisting of residues 74-282 is cleaved off and released as a soluble form into the pericellular milieu. On endothelial cells, the soluble form has been shown to induce bradykinin 1 receptor (B1R) expression by 
binding to surface bound fibrinogen in an autocrine manner (40). Thus, the soluble gClqR is capable of binding to immune cells and modulating various cellular immune responses, including cell proliferation. The anti-proliferative activity of gC1qR has also been demonstrated through the HCV core protein, which binds gC1qR on $\mathrm{T}$ cells and inhibits their growth, highlighting a role for $\mathrm{gClqR}$ in host immune evasion (41). It is likely that the interaction of $\mathrm{C} 1 \mathrm{q}$ with $\mathrm{gClqR}$ provides a negative growth signal, which interferes with normal cell proliferation. This could prove useful in developing targeted therapies where uncontrolled proliferation of immune cells is a critical pathological issue.

The expression of $\mathrm{gC} 1 \mathrm{qR}$ has been detected in several cellular compartments such as mitochondria (42), nucleus (43), and on the cell surface of neutrophils, mast cells, $\mathrm{T}$ and B lymphocytes, endothelial cells, monocytes, and platelets (44-48). However, since $\mathrm{gClqR}$ is devoid of a transmembrane domain, it has been proposed to exert its signal across the membrane through a docking/signal interaction with CD44 (49). We carried out microscopy studies to investigate the colocalization of $\mathrm{gClqR}$ with the gh modules on the cell surface of monocyte-derived macrophages, which revealed gC1qR's presence on the cell surface (Figure 5). We could also observe colocalization of individual gh with gC1qR. Although $\mathrm{C1q}$ has been shown to bind to residues

\section{REFERENCES}

1. Reid KB, Porter RR. Subunit composition and structure of subcomponent C1q of the first component of human complement. Biochem J (1976) 155:19-23. doi:10.1042/bj1550019

2. Kishore U, Reid KB. C1q: structure, function, and receptors. Immunopharmacology (2000) 49:159-70. doi:10.1016/S0162-3109(00)80301-X

3. Garlatti V, Chouquet A, Lunardi T, Vives R, Paidassi H, Lortat-Jacob H, et al. Cutting edge: $\mathrm{C} 1 \mathrm{q}$ binds deoxyribose and heparan sulfate through neighboring sites of its recognition domain. J Immunol (2010) 185:808-12. doi:10.4049/ jimmunol.1000184

4. Erlich P, Dumestre-Perard C, Ling WL, Lemaire-Vieille C, Schoehn G, Arlaud GJ, et al. Complement protein C1q forms a complex with cytotoxic prion protein oligomers. J Biol Chem (2010) 285:19267-76. doi:10.1074/jbc. M109.071860

5. Gaboriaud C, Frachet P, Thielens NM, Arlaud GJ. The human clq globular domain: structure and recognition of non-immune self ligands. Front Immunol (2012) 2:92. doi:10.3389/fimmu.2011.00092

6. Nayak A, Pednekar L, Reid KB, Kishore U. Complement and noncomplement activating functions of $\mathrm{C} 1 \mathrm{q}$ : a prototypical innate immune molecule. Innate Immun (2012) 18:350-63. doi:10.1177/1753425910396252

7. Kishore U, Gaboriaud C, Waters P, Shrive AK, Greenhough TJ, Reid KB, et al. $\mathrm{C} 1 \mathrm{q}$ and tumor necrosis factor superfamily: modularity and versatility. Trends Immunol (2004) 25:551-61. doi:10.1016/j.it.2004.08.006

8. Nayak A, Ferluga J, Tsolaki AG, Kishore U. The non-classical functions of the classical complement pathway recognition subcomponent C1q. Immunol Lett (2010) 131:139-50. doi:10.1016/j.imlet.2010.03.012

9. Kishore U, Ghai R, Greenhough TJ, Shrive AK, Bonifati DM, Gadjeva MG, et al. Structural and functional anatomy of the globular domain of complement protein C1q. Immunol Lett (2004) 95:113-28. doi:10.1016/j.imlet.2004. 06.015

10. Gaboriaud C, Juanhuix J, Gruez A, Lacroix M, Darnault C, Pignol D, et al. The crystal structure of the globular head of complement protein $\mathrm{Clq}$ provides a basis for its versatile recognition properties. J Biol Chem (2003) 278:46974-82. doi:10.1074/jbc.M307764200

11. Kishore U, Kojouharova MS, Reid KB. Recent progress in the understanding of the structure-function relationships of the globular head regions of C1q. Immunobiology (2002) 205:355-64. doi:10.1078/0171-2985-00138
76-93 of $\mathrm{gClqR}$, it appears that there could be additional binding sites on $\mathrm{gClqR}(50)$ involving residues 144-162. This paper together with the other studies, establishing the importance of C1q-gC1qR interaction in disease models, where complement activation is a critical factor in disease progression such as atherosclerosis and Alzheimer's disease, could be relevant for the development of novel therapeutic strategies.

\section{AUTHOR CONTRIBUTIONS}

LP, AP, BP, AT, AK, LK, SA, and GS carried out crucial experiments; HK, MS, and EP provided important reagents and facilities; UK and BG collaboratively designed and supervised most of the experiments, in addition to writing the manuscript.

\section{FUNDING}

This work was supported in part by the Brunel University London, the Deanship of Scientific Research at the King Saud University for funding via Group No. RGP-009 (HK), the National Institute of Allergy and Infectious Diseases R01 AI 060866 and R01 AI-084178 (BG and EP), and NIH/NCI Cancer Center support Grant P30 CA008748 (EP).

12. Kishore U, Leigh LE, Eggleton P, Strong P, Perdikoulis MV, Willis AC, et al Functional characterization of a recombinant form of the C-terminal, globular head region of the B-chain of human serum complement protein, C1q. Biochem J (1998) 333:27-32. doi:10.1042/bj3330027

13. Lim BL, Reid KB, Ghebrehiwet B, Peerschke EI, Leigh LA, Preissner KT. The binding protein for globular heads of complement $\mathrm{C} 1 \mathrm{q}, \mathrm{gClqR}$. Functional expression and characterization as a novel vitronectin binding factor. J Biol Chem (1996) 271:26739-44. doi:10.1074/jbc.271.43.26739

14. Joseph K, Ghebrehiwet B, Peerschke EI, Reid KB, Kaplan AP. Identification of the zinc-dependent endothelial cell binding protein for high molecular weight kininogen and factor XII: identity with the receptor that binds to the globular "heads" of C1q (gC1q-R). Proc Natl Acad Sci U S A (1996) 93:8552-7. doi:10.1073/pnas.93.16.8552

15. Herwald H, Dedio J, Kellner R, Loos M, Muller-Esterl W. Isolation and characterization of the kininogen-binding protein p33 from endothelial cells. Identity with the gC1q receptor. J Biol Chem (1996) 271:13040-7. doi:10.1074/ jbc.271.22.13040

16. Ghebrehiwet B, Lim BL, Peerschke EI, Willis AC, Reid KB. Isolation, cDNA cloning, and overexpression of a $33-\mathrm{kD}$ cell surface glycoprotein that binds to the globular "heads" of C1q. J Exp Med (1994) 179:1809-21. doi:10.1084/ jem.179.6.1809

17. Ghebrehiwet B, Jesty J, Peerschke EI. gC1q-R/p33: structure-function predictions from the crystal structure. Immunobiology (2002) 205:421-32. doi:10.1078/0171-2985-00143

18. Kishore U, Gupta SK, Perdikoulis MV, Kojouharova MS, Urban BC, Reid KB. Modular organization of the carboxyl-terminal, globular head region of human C1q A, B, and C chains. J Immunol (2003) 171:812-20. doi:10.4049/ jimmunol.171.2.812

19. Bally I, Ancelet S, Moriscot C, Gonnet F, Mantovani A, Daniel R, et al. Expression of recombinant human complement $\mathrm{C} 1 \mathrm{q}$ allows identification of the C1r/C1s-binding sites. Proc Natl Acad Sci U S A (2013) 110:8650-5. doi:10.1073/pnas.1304894110

20. Gadjeva MG, Rouseva MM, Zlatarova AS, Reid KB, Kishore U, Kojouharova MS. Interaction of human $\mathrm{C} 1 \mathrm{q}$ with $\mathrm{IgG}$ and $\operatorname{IgM}$ : revisited. Biochemistry (2008) 47:13093-102. doi:10.1021/bi801131h

21. Jiang J, Zhang Y, Krainer AR, Xu RM. Crystal structure of human p32, a doughnut-shaped acidic mitochondrial matrix protein. Proc Natl Acad Sci U S A (1999) 96:3572-7. doi:10.1073/pnas.96.7.3572 
22. Kojouharova MS, Gadjeva MG, Tsacheva IG, Zlatarova A, Roumenina LT, Tchorbadjieva MI, et al. Mutational analyses of the recombinant globular regions of human $\mathrm{Clq} A, \mathrm{~B}$, and $\mathrm{C}$ chains suggest an essential role for arginine and histidine residues in the C1q-IgG interaction. J Immunol (2004) 172:4351-8. doi:10.4049/jimmunol.172.7.4351

23. Peerschke EI, Yin W, Grigg SE, Ghebrehiwet B. Blood platelets activate the classical pathway of human complement. J Thromb Haemost (2006) 4:2035-42. doi:10.1111/j.1538-7836.2006.02065.x

24. Yin W, Ghebrehiwet B, Weksler B, Peerschke EI. Classical pathway complement activation on human endothelial cells. Mol Immunol (2007) 44:2228-34. doi:10.1016/j.molimm.2006.11.012

25. Ghebrehiwet B, Habicht GS, Beck G. Interaction of C1q with its receptor on cultured cell lines induces an anti-proliferative response. Clin Immunol Immunopathol (1990) 54:148-60. doi:10.1016/0090-1229(90)90014-H

26. Tan LA, Yu B, Sim FC, Kishore U, Sim RB. Complement activation by phospholipids: the interplay of factor H and C1q. Protein Cell (2010) 1:1033-49. doi:10.1007/s13238-010-0125-8

27. Ghebrehiwet B, Peterson K, Peerschke EIB, Reddigari SR, Reid KBM. Purification and immunochemical characterization of soluble forms of the 2 types of clq receptors - cclq-r and gclq-r. FASEB (1994) 8:A475.

28. Ghebrehiwet B, Lim BL, Kumar R, Feng X, Peerschke EI. gC1q-R/p33, a member of a new class of multifunctional and multicompartmental cellular proteins, is involved in inflammation and infection. Immunol Rev (2001) 180:65-77. doi:10.1034/j.1600-065X.2001.1800106.x

29. Ghebrehiwet B, Lu PD, Zhang W, Lim BL, Eggleton P, Leigh LE, et al. Identification of functional domains on $\mathrm{gC1Q}-\mathrm{R}$, a cell surface protein that binds to the globular "heads" of C1Q, using monoclonal antibodies and synthetic peptides. Hybridoma (1996) 15:333-42. doi:10.1089/hyb.1996.15.333

30. Ghebrehiwet B, Feng X, Kumar R, Peerschke EI. Complement component C1q induces endothelial cell adhesion and spreading through a docking/signaling partnership of $\mathrm{Clq}$ receptors and integrins. Int Immunopharmacol (2003) 3:299-310. doi:10.1016/S1567-5769(02)00270-9

31. Roumenina LT, Ruseva MM, Zlatarova A, Ghai R, Kolev M, Olova N, et al. Interaction of $\mathrm{C} 1 \mathrm{q}$ with $\operatorname{IgG1}, \mathrm{C}$-reactive protein and pentraxin 3: mutational studies using recombinant globular head modules of human $\mathrm{C1q} A, \mathrm{~B}$, and C chains. Biochemistry (2006) 45:4093-104. doi:10.1021/bi052646f

32. Mei J, Chen B, Yue H, Gui JF. Identification of a C1q family member associated with cortical granules and follicular cell apoptosis in Carassius auratus gibelio. Mol Cell Endocrinol (2008) 289:67-76. doi:10.1016/j.mce.2008.02.016

33. Colombatti A, Spessotto P, Doliana R, Mongiat M, Bressan GM, Esposito G. The EMILIN/Multimerin family. Front Immunol (2012) 2:93. doi:10.3389/ fimmu.2011.00093

34. Carland TM, Gerwick L. The $\mathrm{C} 1 \mathrm{q}$ domain containing proteins: where do they come from and what do they do? Dev Comp Immunol (2010) 34:785-90. doi:10.1016/j.dci.2010.02.014

35. Tom Tang Y, Hu T, Arterburn M, Boyle B, Bright JM, Palencia S, et al. The complete complement of $\mathrm{Clq}$-domain-containing proteins in Homo sapiens. Genomics (2005) 86:100-11. doi:10.1016/j.ygeno.2005.03.001

36. Kishore U, Reid KB. Modular organization of proteins containing Clq-like globular domain. Immunopharmacology (1999) 42:15-21. doi:10.1016/S01623109(99)00011-9

37. Gerwick L, Reynolds WS, Bayne CJ. A precerebellin-like protein is part of the acute phase response in rainbow trout, Oncorhynchus mykiss. Dev Comp Immunol (2000) 24:597-607. doi:10.1016/S0145-305X(00)00016-1

38. Marques G, Anton LC, Barrio E, Sanchez A, Ruiz S, Gavilanes F, et al. Arginine residues of the globular regions of human $\mathrm{C} 1 \mathrm{q}$ involved in the interaction with immunoglobulin G. J Biol Chem (1993) 268:10393-402.
39. Ghebrehiwet B, Lu PD, Zhang W, Keilbaugh SA, Leigh LE, Eggleton P, et al. Evidence that the two $\mathrm{Clq}$ binding membrane proteins, gC1q-R and $\mathrm{cClq}-\mathrm{R}$, associate to form a complex. J Immunol (1997) 159:1429-36.

40. Ghebrehiwet B, Ji Y, Valentino A, Pednekar L, Ramadass M, Habiel D, et al. Soluble $\mathrm{gClqR}$ is an autocrine signal that induces $\mathrm{B} 1 \mathrm{R}$ expression on endothelial cells. J Immunol (2014) 192:377-84. doi:10.4049/jimmunol. 1302031

41. Kittlesen DJ, Chianese-Bullock KA, Yao ZQ, Braciale TJ, Hahn YS. Interaction between complement receptor $\mathrm{gC1} 1 \mathrm{qR}$ and hepatitis $\mathrm{C}$ virus core protein inhibits T-lymphocyte proliferation. J Clin Invest (2000) 106:1239-49. doi:10.1172/ JCI10323

42. Dedio J, Jahnen-Dechent W, Bachmann M, Muller-Esterl W. The multiligand-binding protein $\mathrm{gClqR}$, putative $\mathrm{Clq}$ receptor, is a mitochondrial protein. J Immunol (1998) 160:3534-42.

43. Matthews DA, Russell WC. Adenovirus core protein V interacts with p32 - a protein which is associated with both the mitochondria and the nucleus. J Gen Virol (1998) 79(Pt 7):1677-85. doi:10.1099/0022-1317-79-7-1677

44. Eggleton P, Ghebrehiwet B, Sastry KN, Coburn JP, Zaner KS, Reid KB, et al. Identification of a gClq-binding protein $(\mathrm{gClq}-\mathrm{R})$ on the surface of human neutrophils. Subcellular localization and binding properties in comparison with the cC1q-R. J Clin Invest (1995) 95:1569-78. doi:10.1172/ JCI117830

45. Ghebrehiwet B, Kew RR, Gruber BL, Marchese MJ, Peerschke EI, Reid KB. Murine mast cells express two types of $\mathrm{Clq}$ receptors that are involved in the induction of chemotaxis and chemokinesis. J Immunol (1995) 155:2614-9.

46. Gupta S, Batchu RB, Datta K. Purification, partial characterization of rat kidney hyaluronic acid binding protein and its localization on the cell surface. Eur J Cell Biol (1991) 56:58-67.

47. Peerschke EI, Reid KB, Ghebrehiwet B. Identification of a novel 33-kDa C1qbinding site on human blood platelets. J Immunol (1994) 152:5896-901.

48. Peerschke EI, Ghebrehiwet B. Platelet membrane receptors for the complement component C1q. Semin Hematol (1994) 31:320-8.

49. Feng X, Tonnesen MG, Peerschke EI, Ghebrehiwet B. Cooperation of C1q receptors and integrins in C1q-mediated endothelial cell adhesion and spreading. J Immunol (2002) 168:2441-8. doi:10.4049/jimmunol.168.5.2441

50. Ghebrehiwet B, Jesty J, Vinayagasundaram R, Vinayagasundaram U, Ji Y, Valentino A, et al. Targeting gC1qR domains for therapy against infection and inflammation. Adv Exp Med Biol (2013) 735:97-110. doi:10.1007/978-14614-4118-2_6

Conflict of Interest Statement: The authors declare that the research was conducted in the absence of any commercial or financial relationships that could be construed as a potential conflict of interest.

The reviewer RS and handling Editor declared their shared affiliation, and the handling Editor states that the process nevertheless met the standards of a fair and objective review.

Copyright (c) 2016 Pednekar, Pathan, Paudyal, Tsolaki, Kaur, Abozaid, Kouser, Khan, Peerschke, Shamji, Stenbeck, Ghebrehiwet and Kishore. This is an open-access article distributed under the terms of the Creative Commons Attribution License (CC BY). The use, distribution or reproduction in other forums is permitted, provided the original author(s) or licensor are credited and that the original publication in this journal is cited, in accordance with accepted academic practice. No use, distribution or reproduction is permitted which does not comply with these terms. 